\title{
Dementia-Friendly Heritage Settings: A Research Review
}

\section{Introduction}

With increased numbers of people living with dementia, it is becoming a collosal challenge that can no longer be overlooked in the United Kingdom. According to the Alzheimer's Society Annual Report (2016/17), there were an estimated 850,000 people living with dementia in the UK in 2015. This number is expected to increase to over 1 million by 2025 and over 2 million by 2051. Notably, more than 40,000 people under the age of 65 in the UK are currently living with early-onset dementia (Prince et al., 2014).

Dementia is characterised by a progressive decline in a person's physical, cognitive, social and emotional capabilities. The deterioration can lead to impaired memory, learning and reasoning, stress, visuo-perceptual problems, and difficulty in adjusting to the sensory/ mobility impairment that can accompany ageing. As a result, people living with dementia need more support in activities of daily life and have an increased need for care, which can be stressful for both the person with dementia and their care supporter (van der Linde et al., 2013). Thus, the support should be designed to alleviate stress, and to maintain and enhance the wellbeing of people living with dementia and those caring for them. This is particularly important to ensure social inclusion, which the World Bank (2019) defines as improving the terms on which individuals and groups take part in society - improving the ability, opportunity and dignity of those disadvantaged on the basis of their identity - which in turn improves wellbeing and self esteem.

Built heritage refers to the preservation of monuments and historic buildings, often coveting structures with statutory protection by legislation such as the Ancient Monument Acts, Archaeological Areas Acts, Monument Ordonantie and National Heritage Acts (Herbert 1989; Prentice, 1993). Such recognition is granted if the built structure(s) is deemed to foster historic significance or architectural merit (Herbert, 1989), and as a result, the legislation leads to an increase in the awareness, protection, preservation, restoration and the display of its heritage properties (Poria et al, 2011). For the purposes of this review, 'heritage' is defined as an 'aspect of the worth or importance attached by people to qualities of places, categorised as aesthetic, evidential, communal or historical value' (Historic England, n.d.). A report by Fujiwara, Cornwall and Dolan (2014) evidents that there is an association between heritage site visits and visitor wellbeing. The report emphasises that visiting heritage sites has a substantial positive connection with the life satisfaction of its visitors, and concludes that this connection is more significant in terms of impact than from participation in sports and the arts. Work by English Heritage suggests that heritage assets have the ability to create 'pride', 'a sense of place' and 'a sense of community' by linking the present with the past (Wineinger, 2011; English Heritage, 2000; English Heritage, 2006; English Heritage, 2014). Further, research undertaken by Age UK has recognised that engagement with creative and cultural activities including heritage, makes a significant contribution to one's overall wellbeing compared to other factors (Age UK, 2017; Maeer, Robinson and Hobson, 2016). The value of heritage has been described as a source of identity, and a source of character and distinctiveness (Historic England, 2016). Thus, the provision of appropriate opportunities for people with dementia and their care supporters to engage in visits to heritage sites can provide valuable wellbeing and health benefits. However, the relationship between built heritage and 
tourism is plagued with contradictions and conflict between conservation goals and those for financial profit (Nuryanti, 1996). Some researchers have argued that heritage and tourism are incompatible (Boniface, 1998; Berry, 1994) and a conflict relationship is inevitable (Daniel, 1996). The scant lack of financial resources to support inclusivity in built heritage, and the argument that some heritage cannot be adapted, often leads to only limited opportune for people with dementia. Thus, there is a need to understand existing research and wellbeing programmes so that it can be focalled in the future to support built heritage tourism in a way that it is inclusive to all by directing policy, research funding, academic research and built heritage decision makers. This research review presents an analysis of the available literature on wellbeing programmes designed for people living with dementia and their care supporters, with particular reference to programmes in heritage settings and the resulting impact for users.

\section{Method}

This research review draws upon the principles of a systematic review in its approach to searching for peer-reviewed material relating to wellbeing programmes for people with dementia and their care supporters, that are delivered in museum, historic or heritage settings. The selection criteria of the literature was primarily based on the direct relevance to the subject, and also a number of studies which focused on related subjects due to their substantial importance. Research reviews have been more popular in recent years to understand the current status of existing research and identify gaps/ new research opportunities (for example, see Delzendeh et al, 2017 and Weiss et al, 2017).

Review papers usually follow a process of 'search' for relevant publications, utilising citation indexes against pre-determined criteria for eligibility and relevance to form an inclusion set relating to the research area. To reduce bias in this process, an objective and transparent approach for research synthesis was adopted, including both quantitative analysis and qualitative reviews. Searches were conducted using Science Direct, Web of Science and Ovid Abstracts, and four databases accessed via EBSCO Host (Academic Search Premier, CINAHL, Hospitability and Tourism, and MEDLINE) from 2010 to date, using the search terms listed in Table 1. Only a limited number of studies specific to wellbeing programmes for people with dementia delivered within heritage settings were identified. There are examples in the UK and elsewhere of wellbeing programmes provided by arts and heritage organisations targeting different service user groups, which feature the viewing and/ or handling of art works, artefacts and objects, sometimes with associated arts and crafts activities. These are sometimes delivered onsite (within the museam, historic or heritage setting) and sometimes in residential, health or care facilities. Therefore, the terms for the database searches were developed to include such programmes for older people and people with cognitive impairment, and similar programmes delivered by specialised museum/ heritage/ gallery staff in any care settings.

\section{Table 1: Research Review Search Terms}

\section{Search Results}

On the basis of the inclusion criteria detailed in Table 1, the titles and abstracts of the journal papers were screened for relevance. A total of 185 journal papers were recovered from various sources (see Table 2). If there was clear relevance, the full paper was retrieved for 
detailed analysis. After screening of titles, abstracts and removal of duplications, fourteen papers were found to meet the inclusion criteria, with a further five studies identified through 'snowballing' (i.e. via reference lists in the retrieved papers), making a total of nineteen papers for review; these are summised in Table 3.

\section{Table 2: Research Review Results}

Table 3: Summary of the Literature

\section{Overview of the research review}

Table 3 details the nineteen papers in chronological publication date order, commencing with the most recent first; each paper was subsequently assigned with a number to ease identification.

Ten of the nineteen studies relate to people with dementia and their care givers (i.e Camic et al (2015), Flatt et al (2015), Johnson et al (2015), Camic et al (2014), Zeilig et al (2014), Camic \& Chatterjee (2013), Eekelaar et al (2012), National Museams Liverpool (2012), MacPherson et al (2009) and Mittleman \& Epstein (2009)). Of the other nine papers, three concern patients with mental health problems and their care supporters; three relate to older people with cancer; and three to older people in general.

Sixteen of the papers report evaluation studies concerning wellbeing programmes based upon art viewing, including discussion of the selected art object (i.e. Camic et al (2015), Flatt et al (2015), Camic et al (2014), Eekelaar et al (2012), Roberts et al (2011), MacPherson et al (2009) and Mittleman \& Epstein (2009)) or object handling (i.e. Roe et al (2016), Smiraglia (2015), Solway et al (2015), Thomson et al (2012a), Thomson et al (2012b), Ander et al (2012) and Lanceley et al (2012)). Two of these are internal evaluation reports, one by the National Museum Liverpool (2012) and one by the Museum of Modern Arts (MOMA) in New York (Mittleman \& Epstein , 2009). The Liverpool Project (National Museams Liverpool, 2012) evaluates a training programme designed to equip museum staff and carers at the National Museum to deliver sensory and arts sessions to people with dementia. Six of the projects involve a related art or craftmaking activity completed during the session (i.e. Roe et al (2016), Camic et al (2015), Flatt et al (2015), Camic et al (2014), Eekelaar et al (2012) and Roberts et al (2011)). Of the other three papers, one is a literature review (i.e. Zeilig et al (2014)), another is a comparative study of two museum based activities (i.e. Johnson et al (2015)), and the third is a discussion paper (i.e. Camic \& Chatterjee (2013)) considering the benefits of museum and art based activities as a non-pharmacological intervention to promote health and wellbeing.

Ten of the programmes are delivered in museum or art galleries (i.e. Roe et al (2016), Camic et al (2015), Flatt et al (2015), Johnson et al (2015), Camic et al (2014), Eekelaar et al (2012), National Museams Liverpool (2012), Roberts et al (2011), MacPherson et al (2009) and Mittleman \& Epstein (2009)), six take place in hospital or care settings (i.e. Solway et al (2015), Zeilig et al (2014), Thomson et al (2012a), Thomson et al (2012b), Ander et al (2012) and Lanceley et al (2012)), and one in an independent living community facility (i.e Smiraglia 
(2015)). None of the projects is delivered in a heritage setting. Three projects are based in USA (i.e. Flatt et al (2015), Smiraglia (2015) and Mittleman \& Epstein (2009)), one in Australia (i.e. MacPherson et al (2009)) and the rest in the UK.

Of the sixteen evaluation studies, eight studies employ qualitative methods (i.e Roe et al (2016), Camic et al (2015), Solway et al (2015), Ander et al (2013), National Museams Liverpool (2012), Ander et al (2012), Lanceley et al (2012) and Roberts et al (2011)), and an equal number of studies states that they deploy mixed methods in their evaluation (i.e. Flatt et al (2015), Smiraglia (2015), Camic et al (2014), Eekelaar et al (2012), Thomson et al (2012a), Thomson et al (2012b), MacPherson et al (2009) and Mittleman \& Epstein (2009)).

Data was extracted from the identified papers relating to the country where the study was conducted, the programme design, study objectives, methods used, and the findings from each study, with particular reference to the concerns of the Sensory Palaces programme evaluation; i.e:

- Programme design (e.g. activities, participants, number, staff support, staff number, staff training, and disciplines facilitator expertise).

- Issues related to setting or environment (e.g. the nature of setting, atmosphere value, safety, access, wayfinding etc.).

- The impact on the wellbeing of the participants (e.g. including and social enhancement, intellectual enhancement, reminiscence, positive feeling, engagement and enjoyment, tactile stimulation etc.).

Findings not related to the above categories were also noted, and are presented in this research review below.

\section{Review of the literature}

The 19 identified papers relevant to this research review were analysed thematically to identify key messages in the literature. Table 4 provides a summary of the analysis relating to each of the categories.

\section{Table 4: Research Review Findings by Category}

The majority of the studies included in this research review emphasised the wellbeing benefits of attending programme sessions for the participants, and explicitly for those people living with dementia and their care supporters (i.e. Roe et al (2016), Camic et al (2015), Flatt et al (2015), Johnson et al (2015), Smiraglia (2015), Solway et al (2015), Camic et al (2014), Zeilig et al (2014), Ander et al (2013), Camic \& Chatterjee (2013), Eekelaar et al (2012), Thomson et al (2012a), Thomson et al (2012b), Ander et al (2012), Lanceley et al (2012), Roberts et al (2011), MacPherson et al (2009) and Mittleman \& Epstein (2009)). Participants reported that they were treated with dignity, felt a sense of achievement by learning new skills and welcomed the opportunities for social interaction (MacPherson et al., 2009). Lanceley et al., (2012) emphasised the psychological benefits to the participants. Fourteen studies discussed the importance of carefully structuring/ design of such programmes, not only providing social, 
sensory, tactile stimulation but also intellectually stimulating, enjoyable, engaging via activities designed to accommodate the needs of participants (i.e. Roe et al (2016), Camic et al (2015), Flatt et al (2015), Smiraglia (2015), Solway et al (2015), Camic et al (2014), Ander et al (2013), Camic \& Chatterjee (2013), Eekelaar et al (2012), Thomson et al (2012b), Ander et al (2012), Roberts et al (2011), MacPherson et al (2009) and Mittleman \& Epstein (2009)).

\subsection{Programme design}

- Session design/ structure

Fourteen papers highlighted the wellbeing benefits of including physical objects in the sessions (i.e Roe et al (2016), Camic et al (2015), Flatt et al (2015), Smiraglia (2015), Solway et al (2015), Camic et al (2014), Ander et al (2013), Camic \& Chatterjee (2013), Eekelaar et al (2012), Thomson et al (2012b), Lanceley et al (2012), Roberts et al (2011), MacPherson et al (2009) and Mittleman \& Epstein (2009)). Most demonstrated the importance of touchable, physical objects as major beneficial components of the programmes (i.e Flatt et al (2015), Smiraglia (2015), Solway et al (2015), Camic et al (2014), Ander et al (2013), Ander et al (2012), Lanceley et al (2012) and Roberts et al (2011)). The Heritage in Hospitals research project, reported by Ander et al., (2013), reported on the therapeutic role of museum objects in a hospital setting. It stated that the objects should be easy to handle, taking into consideration the physical capabilities of the participants. The significance of physical interaction with objects i.e. through touch, sight and sound, offers a richer experience to the participants (i.e. Smiraglia (2015), Solway et al (2015), Ander et al (2012), Lanceley et al (2012) and Roberts et al (2011)), and this literature suggests that the use of heritage objects provides a sense of identity, continuity, and stability (i.e. Camic et al (2015), Flatt et al (2015), Solway et al (2015) and Ander et al (2013)). Taking a physical object and engaging with that object through various senses can be a powerful experience, according to Ander et al (2012). This study also stressed that the museum object handling sessions provided both 'stimulation and distraction,' for participants, both of which are extremely significant for wellbeing. It has been observed that that during heritage-object handling sessions, people with impairments, with staff support, were able to engage with the object at various levels, including in a creative manner, and to consider what their disease meant to them (i.e Solway et al (2015) and National Museams Liverpool (2012)). The skills of people with dementia should not be underestimated while designing these sessions. There is often an over emphasis on their difficulties and problems rather than focussing on their actual abilities. If the sessions are not designed appropriately they could lead to disengagement of the participant (Solway et al (2015)). Two studies suggested that in order to provide better opportunities for participants, the number of participants attending a particular session should be purposely small (i.e. Flatt et al (2015) and Mittleman \& Epstein (2009)). This is not only beneficial for the people with dementia but also helps the staff to provide appropriate care and support during the session (Johnson et al, 2015).

\section{- Staffing}

Five studies included in the review suggested that sessions should be designed with an appropriate number of staff i.e. providing sufficient support to people with dementia and their care supporters (i.e. Roe et al (2016), Camic et al (2015), Flatt et al (2015), Camic \& Chatterjee (2013) and MacPherson et al (2009)). The studies also highlighted the importance of staff flexibility, for example, by varying or interrupting planned sessions to provide emotional support to the participants if needed (i.e. Roe et al (2016), Camic et al (2015) and Flatt et al (2015)). This not only helps participants feel more relaxed, but provides them with a 
psychological benefit such as feeling special (i.e. Flatt et al (2015) and Camic \& Chatterjee (2013)). Sessions designed with sufficient numbers of staff to support the participants can additionally provide a sense of psychological security (Ander et al, 2013).

- Staff training

Staff must have an understanding of the impact the condition has on people with dementia. This includes consideration of how the individual person with dementia might think and feel. It will be helpful if the staff can offer support according to participants' needs as far as possible. Therefore, trained facilitator and staff support is necessary as it will provide a sense of safety and security to the participants (i.e. Roe et al (2016), Thomson et al (2012b), National Museams Liverpool (2012), Roberts et al (2011) and Mittleman \& Epstein (2009)) during programme sessions.

\subsection{Impact on wellbeing}

\section{- Social Enhancement}

Twelve studies supported the social benefits of attending such programmes from the perspective of people with dementia, care supporters and from the perspective of the staff involved (i.e. Roe et al (2016), Camic et al (2015), Flatt et al (2015), Smiraglia (2015), Camic et al (2014), Zeilig et al (2014), Ander et al (2013), Camic \& Chatterjee (2013), Eekelaar et al (2012), Ander et al (2012), MacPherson et al (2009) and Mittleman \& Epstein (2009)). The studies highlighted the perspective of care supporters, which suggested that participating in such sessions/ groups helped in reducing their sense of isolation. Care supporters felt that attendance together with their partner enhanced their identity as a couple and not just as a care supporter for a person with dementia, which could be a lonely experience. Several studies reported that care supporters appreciated that the sessions helped both carers and people with dementia to feel less alone, through meeting other people in similar situations, and feeling supported by other carers (i.e. Camic et al (2015), Flatt et al (2015), Solway et al (2015), Ander et al (2013) and Thomson et al (2012a)). Participation not only provided a shared experience but also a strong sense of returning to 'normality', and enjoying activities as they did prior to the onset of the dementia. Inclusion is also aided by taking the service out into various community settings, particularly for groups who may feel stigma in public spaces, related to social views about the illness.

\section{- Learning}

Communication, storytelling, discussion, group participation, and improved verbal fluency, allowed for meaningful communication and understanding to occur, be it through making art, discussing paintings in the gallery, or having the opportunity to socialise during the sessions (i.e Ander et al (2013), Eekelaar et al (2012) and Roberts et al (2011)). Six studies identified shared learning, and engagement between people with dementia and their care supporters have a stimulating impact on the participants (i.e. Smiraglia (2015), Solway et al (2015), Zeilig et al (2014), Ander et al (2013), Thomson et al (2012b) and Mittleman \& Epstein (2009)). For some, art making encouraged a valued manner of interaction and understanding/ collaboration for pariticipants.

\section{- Psychological benefits}


Eighteen studies highlighted some psychological benefit of participating in such sessions; for example, positive feelings, personhood, sense of self, autonomy, control, comfort, and a sense of continuity (i.e. Roe et al (2016), Camic et al (2015), Flatt et al (2015), Johnson et al (2015), Smiraglia (2015), Solway et al (2015), Camic et al (2014), Zeilig et al (2014), Ander et al (2013), Camic \& Chatterjee (2013), Eekelaar et al (2012), Thomson et al (2012a), Thomson et al (2012b), Ander et al (2012), Lanceley et al (2012), Roberts et al (2011), MacPherson et al (2009) and Mittleman \& Epstein (2009)). The people who participated in the programmes reported that these sessions elicit enjoyment and improvements in mood, and help them to participate in activities in an enjoyable manner (i.e. Camic et al (2015), Johnson et al (2015), Thomson et al (2012b) and Ander et al (2012)). For some, memories were stimulated by the object handling activities, including memories of time spent with family or friends (i.e. Eekelaar et al (2012), Roberts et al (2011) and MacPherson et al (2009)). Smiraglia (2015) reports on how participants talked about their experiences of doing photography with their families. Further benefits of sessions could include a general sense of achievement, enhanced learning abilities, confidence, and connections with past memories, gaining a sense of identity, a feeling of being valued and other emotional benefits (i.e. Smiraglia (2015), Solway et al (2015), Ander et al (2013), Camic \& Chatterjee (2013), Ander et al (2012), Lanceley et al (2012) and Mittleman \& Epstein (2009)). There was evidence of significant improvements in positive emotions, wellbeing and happiness, and in patients' perceptions of their own health, and positive impacts on relationships among staff, patients and their care supporters (i.e. Solway et al (2015) and Ander et al (2013)).

\subsection{Programme Settings}

- Significance of the programme setting

Within the literature reviewed, there was some limited consideration of the significance of the settings in which the sessions took place, and little specifically about historic or heritage settings and their impact on participants. Where the setting was considered, the studies referred to two main aspects of the built environment, although these are not developed in detail in this body of literature. One relates to the ways in which attending programmes in galleries or museums settings made participants feel part of a luxurious, prestigious setting. Attendance not only gave them opportunity to visit these spaces, but also to feel accepted back into society, to feel valued and to regain a sense of identity, often lost on the journey into the illness. The second element concerns the physical aspects of the built environment such as anxieties about wayfinding and navigating through various spaces (i.e. Roe et al (2016) and Mittleman \& Epstein (2009)).

\section{- 'Gallery/ Museum' settings}

Eight studies found that using gallery or museum settings as venues for delivering such sessions help to make the overall experience much richer for the participants (i.e. Camic et al (2015), Flatt et al (2015), Camic et al (2014), Ander et al (2013), Camic \& Chatterjee (2013), Ander et al (2012), Roberts et al (2011) and Mittleman \& Epstein (2009)). These studies stressed participants' experience of museums and art galleries as special settings for programme delivery, described, for example, as privileged, quiet, special, welcome, important, and as having architectural grandeur. Participants in some studies emphasised the significance of such settings as a 'valued place' which takes them away from everyday activity and worries about the illness (i.e. Camic et al (2015) and Camic et al (2014)). The literature 
included in this review suggests that art-viewing or object handling sessions delivered in a prestigious setting can make participants feel privileged, welcome and important, and provided them with chance to visit such famous settings, which they might not otherwise do (i.e. Camic et al (2015), Camic et al (2014), Camic \& Chatterjee (2013) and Mittleman \& Epstein (2009)). The art gallery/ museum setting was used as an enabling and distinctive environment supported participants to feel like active members of society, who are socially included and valuable as people (Camic et al (2014)).

- Physical aspects of environment

It is documented in four studies that the physical characteristics of the environment are also important when considering certain sites as venues in which to deliver such programmes (i.e. Roe et al (2016), Camic \& Chatterjee (2013), Roberts et al (2011) and Mittleman \& Epstein (2009)). Two studies highlighted that concerns about wayfinding/ navigation through various spaces concerns have been mentioned by participants (i.e. Roe et al (2016) and Mittleman \& Epstein (2009)). It is also recognised that if information is shared in advance and appropriate staff support is provided on the day, this can help improve safety and provide a much more relaxed environment for the participants (i.e. Camic \& Chatterjee (2013), Roberts et al (2011) and Mittleman \& Epstein (2009)).

\subsection{Other Issues in the Literature}

- Programme sustainability and development

Six studies raised the challenges of maintaining and developing programmes beyond pilot phases, and highlighted the future feasibility of the programmes, considering new perspectives, alternative approaches for support, and collaborations between the health sector, heritage sector and universities to deliver such programmes (i.e. Roe et al (2016), Camic \& Chatterjee (2013), National Museams Liverpool (2012), Ander et al (2012), MacPherson et al (2009) and Mittleman \& Epstein (2009)). Evaluation evidence of programmes in collaboration with universities could help to justify their wellbeing impact, which could further help in substantiating the need and the necessary resources for funders to deliver more of these sessions for people with dementia.

\section{- Public awareness of dementia}

Five studies discussed benefits relating to the development of new insights, acceptance and awareness about dementia in general and people with dementia in particular (i.e. Camic et al (2015), Zeilig et al (2014), National Museams Liverpool (2012), Roberts et al (2011) and Mittleman \& Epstein (2009)). Staff participation in the studies have highlighted that running programmes of this kind for groups of people with specific needs, such as people living with dementia, has enhanced their understanding of dementia and increased general awareness about the disease. It further aided them to understand the perspectives of the people with dementia and their care supporters. With better understanding and training, the facilitators are enabled to deliver the sessions in a better way, incorporating sensory approaches, enhanced communication i.e. more listening, slowing down and responding to participants' need and moving at their pace (National Museams Liverpool (2012)).

- Inclusion 
Seven studies emphasised the significance of people with dementia and their care supporters to feel "normal", i.e. feeling part of society, and the value of activities such as these programmes provide structure and stability to their lives (i.e. Camic et al (2015), Zeilig et al (2014), Camic \& Chatterjee (2013), Eekelaar et al (2012), Thomson et al (2012b), Roberts et al (2011) and Mittleman \& Epstein (2009)). Further this could be through enriched relationships between the facilitator and the person with dementia. The studies have also highlighted that participants felt that these sessions opened doors to different experiences, giving them more confidence to access other opportunities, and for carers also so that they were assured that the person with dementia would be treated with dignity.

\section{- Barriers and concerns}

Five studies acknowledged various concerns about specific programmes, such as insufficient information sharing in advance with the participants, for example, about the breaks/ time allocation to each session, the routes they will follow, entrances to buildings and concerns about background noises. One study reflected on whether the visual stimulation of art enabled the person with dementia to remain engaged in the process (i.e. Mittleman \& Epstein (2009)). Some studies also highlighted worries expressed by participants about whether they would be capable of completing the activities included in the sessions (i.e. Camic et al (2015), Flatt et al (2015), Smiraglia (2015), MacPherson et al (2009) and Mittleman \& Epstein (2009)). One study stressed that sometimes the enthusiasm of the carer to participate may discourage the person with dementia to respond (i.e. Mittleman \& Epstein (2009)).

\section{Discussion}

The analysis of the literature in this research review demonstrates that participative arts and object handling programmes are able to contribute positively to the lives of those living with dementia in various ways, and are being increasingly suggested as a valuable activity as a means to reduce the negative impacts of the illness. This review supports conclusions drawn elsewhere; that is, that such programmes appear to be able to support communication, encourage creative capabilities, stimulate new learning particularly 'in the moment', improve cognitive function, increase confidence and self-esteem, social participation (Museums Libraries \& Archives, 2010) and generate a sense of autonomy amongst other acknowledged benefits such as social, tactile, intellectual, sensory stimulation (UK Department of Health, 2009). Chatterjee, Vreeland and Noble (2009) confirmed that museum objects handling sessions enhanced self-reported patient life contentment and health status of in-patients in hospital settings. Rosenberg (2009) reported on a study at New York's Museum of Modern Art, in which people in the early stages of Alzheimer's disease and their care supporters participated in art viewing sessions in the museum, facilitated by trained museum staff. Research has also reported increased sustained attention, engagement, and communication during arts-based activities (Kinney and Rentz, 2005; Musella et al., 2009; Rosenberg, 2009). The physical spaces and social contexts in which art and museum objects are viewed or handled can influence learning and social interactions (Falk and Dierking 2000). For example, the therapeutic significance of the art gallery setting for care supporters was justified in a study that involved people caring for a relative with a severe and longstanding mental health problem (Roberts, Camic \& Springham, 2011). 'House of Memories' is a museum-led dementia awareness programme run by the National Museums Liverpool, which offers training, access to resources, and museum-based activities to allow care supporters to deliver personcentered care for people with dementia (House of Memories, 2017). Silverman (2010) 
emphasises the importance of museums as places of stimulation, and suggests that museum settings can contribute to participants' health in many ways, such as support relaxation; physiological benefits, emotions support and encourage identity. Several major international galleries have used their venues for interventions, with the aim to include promotion of health and well-being. Examples include programmes run by the National Gallery of Australia, Sydney, the Museum of Modern Art (MoMA), New York, Whitworth Gallery in Manchester and Tate Britain, London (Roe et al.,2016; Camic, Roberts \& Colbert, 2009). More recently, Historic Royal Palaces have published a guide to making heritage sites more dementiafriendly, based on case studies from a number of heritage sites in the UK (Historic Royal Palaces, 2017).

Within the papers reviewed in this research review, there is evidence of broad agreement about aspects of participatory arts and cultural programmes for people with dementia and their carers, including design principles, and areas of benefit for participants. This literature suggests that setting such programmes in publicly accessible cultural, architecturally important or historical settings adds something to the experiences of the participants; however, this is not explored in depth or detail, and is not a specific research question for any of the studies reviewed.

The review has suggested a wide research landscape to address the impact of multidimensional enhancement experience of senses i.e. via use of spaces/ setting/ artsbased activities/ handling objects have on wellbeing and health of people living with dementia. For people with dementia, it is vital to explore into all the senses to generate memories. It may possibly be a photograph to look at, an object to touch, music to listen to or something to smell or taste can take anyone back in time, a lot to a very specific memory. Such multisensory programs can have psychological benefits, but very few have been studied empirically (Olazaran et al., 2010; National Collaborating Centre for Mental Health, 2007). The evidence base could be strengthened. In particular, studies that take place over longer time periods with more diverse groups of people with dementia and that use a variety of evaluative methods (several studies have confirmed the effectiveness of combining qualitative with quantitative measures) are necessary (Cox, Burns \& Savage, 2004).

Despite the apparent potential of these programmes, there is a major research gap; on the whole, though the scientific base is increasing, there is largely a lack of rigorous methodology to validate the benefits, and research findings are mixed. Complex interventions such as these are often implemented in a varied style by different investors (with different expertise), to varied populations and in dissimilar settings, all of which can affect the results derived (Pawson et al., 2004). This inconsistency increases challenges in terms of recognising an appropriate programme model.

In addition, and more apparent for the built environment setting, there was scant research available to support guidance on the physical aspects of the environment. Wayfinding and navigation was identified and raised as particular concerns to those living with dementia, and there is research available in the general built environment domain that can be applied to built heritage settings (for example, see Arthur \& Passini, 1992). However, no research was notably identified that addressed cognitive impairments over and above physical impairments that 
regulations governing disability usually address. An accessible or inclusive building design should not disable any user; it should enable the independent and equal use of a facility by all (Wu et al, 2004; Wu et al, 2007). With the introduction of the Disability Discrimination Act 1995 in the UK, the consideration of issues such as access and inclusive design has become more important, but has failed to address aspects related directly to dementia. The physical environment has be proven to alter psychosocial processes (Evans, 2003). Therefore, longitudinal studies are needed to examine the potential role of the physical environment heritage setting on dementia; and must include aspects such as lighting, temperature, acoustics and materiality, so that they can be understood and suitably adapted to support the wellbeing of those living with dementia.

Further research is also necessary to examine how the heritage built environment setting can facilitate and encourage and improve other aspects of general health and wellbeing, for example, through encouragement of walking and self-exploration.

Finally, it was perhaps surprisingly that there was little discourse in the reviewed literature that addressed the argument that some heritage cannot be adapted, generally leading to only limited opportune for people with dementia, particularly within limited financial resources in heritage management overall.

It is acknowledged that the key words in this research review (Table 1) were carefully and purposely selected to ensure that the outputs identified addressed the research aim and scope of this paper. The resultant 185 papers (see Table 2) were subsequently manually narrowed to 19 papers, representing a $10 \%$ inclusion rate based on detailed manual investigation within the project scope. Thus, 19 papers is recognized in itself as limited in number, and is based on the number of researches that have been undertaken in this area since 2010, which highlights the scant attention paid to dementia-friendly heritage settings generally.

\section{Conclusion}

This research review demonstrates that there is a growing body of evidence to suggest that the arts, cultural and heritage sectors can make a significant contribution to improve the health and wellbeing of people in general, including for people living with dementia and their carers. This review supports conclusions drawn elsewhere; that is, that such programmes appear to be able to support communication, encourage creative capabilities, stimulate new learning particularly 'in the moment', improve cognitive function, increase confidence and self-esteem, social participation (Museums Libraries \& Archives, 2010) and generate a sense of autonomy amongst other acknowledged benefits such as social, tactile, intellectual, sensory stimulation (UK Department of Health, 2009). This is particularly important to enable social inclusion for all, and improved well-being and self-esteem of those suffering with dementia. However, there is limited robust empirical and qualitative evidence about the impact and contribution of the settings, in particular heritage settings, such as historical sites and buildings in which such programmes or activities take place. The little work that has been conducted suggests that 
heritage settings could be used as integral components of an intervention i.e. forming a link with the past memories of the participants, but on the whole the research lacks rigorous methodology to substantiate the benefits. In addition, as funding for heritage built environment settings is largely limited, and plagued with conflict between conservation goals and those to support inclusivity, it should also be focalled in the future to support:

- Wayfinding and navigation in heritage settings against the benefits of self-exploration for those living with dementia

- Cognitive impairments in heritage settings, including aspects of lighting, temperature, acoustics and materiality, so that they can be understood and suitably adapted to support the wellbeing of those living with dementia 


\section{$\underline{\text { References }}$}

Age UK. (2017). A Summary of Age UK's Index of Wellbeing in Later Life. London. Age UK. https://www.ageuk.org.uk/Documents/EN-GB/For-professionals/Research/AgeUKWellbeing-Index-Summary-web.pdf?dtrk=true

Alzheimer's Society (2017) Annual Review 2016/17. London. Alzheimer's Society. https://www.alzheimers.org.uk/download/downloads/id/3718/alzheimers society annual rev iew 201617.pdf

Ander, E. L., Thomson, G., Noble, A., Lanceley, A., Menon, U \& Chatterjee. H. (2012). Heritage, Health and Well-Being: Assessing the Impact of a Heritage Focused Intervention on Health and Well-Being. International Journal of Heritage Studies. 19 (12), pp.229-249.

Ander, E.E., Thomson, L.J.M., Blair, K., Noble, G., Menon, U., Lanceley, A. \& Chatterjee, H.J. (2013) Using Museum Objects to Improve Wellbeing in Mental Health Service Users and Neurological Rehabilitation Clients. British Journal of Occupational Therapy, 76(5), 208-216.

Arthur, P. \& Passini, R. (1992) Wayfinding: People, Signs and Architecture. McGraw-Hill, New York.

Beard, R. (2011). Art therapies and dementia care: A systematic review. Dementia. 11(5), pp.633-656.

Camic, P.M., Roberts, S. \& Colbert, S. (2009). Gallery as laboratory: Experiments in new social practices. Advancing Arts and Mental Health Conference, May 2009, Tate Britain, London, UK.

Camic, P.M., Williams, C.M., \& Meeten, F. (2011). Does a 'Singing Together Group' improve the quality of life of people with a dementia and their carers? A pilot evaluation study.

Dementia, 12(2) pp.157-176.

Camic, P. M. \& Chatterjee, H. J. (2013) 'Museums and art galleries as partners for public health interventions,' Perspectives in Public Health. 133(1), pp. 66-71.

Camic, P.M., Tischler, V. \& Pearman, C.H. (2014) Viewing and Making Art Together: a MultiSession Art Gallery Based Intervention for People with Dementia and their Carers. Aging \& Mental Health, 18:2, 161-168.

Camic, P.M., Baker, E. \& Tischler, V. (2015) 'Theorising how art gallery interventions impact people with dementia and their caregivers,' The Gerontologist. pp.1-10.

Chatterjee, H., Vreeland, S., \& Noble, G. (2009). Museopathy: Exploring the Healing Potential of Handling Museum Objects. Museum and Society, 7(3) p. 164-177. Available at: $<$ https://www108.lamp.le.ac.uk/ojs1/index.php/mas/article/view/145 
Cox, H., Burns, I. \& Savage, S. (2004) 'Multisensory environments for leisure: promoting wellbeing in nursing home residents with dementia,' Journal of Gerontological Nursing. 30 (2), pp. 37-45.

Delzendeh, E., Wu, S., Lee, A. \& Zhou, Y. (2017) The Impact of Occupants' Behaviours on Building Energy Analysis: A Research Review. Renewable and Sustainable Energy Reviews, 80, 1061-1071.

Eekelaar, C., Camic, P.M., \& Springham, N. (2012). Art galleries, episodic memory and verbal fluency in dementia: An exploratory study. Psychology of Aesthetics, Creativity, and the Arts. 6(3), pp.262-272.

English Heritage. (2000) Power of Place: The Future of the Historic Environment. London: English Heritage for the Historic Environment Steering Group.

English Heritage. (2006) Heritage Counts: The State of England's Historic Environment 2006. London: English Heritage.

English Heritage, 2014. Heritage Counts 2014: The Value and Impact of Heritage. [pdf] Available at: https://content.HistoricEngland.org.uk/content/heritage-counts/ pub/2190644/value-impact-chapter.pdf [Accessed September 2017].

Evans, G.W. (2003) The Built Environment and Mental Health. Journal of Urban Health, 80(4), 536-555.

Falk, J.H. \& Dierking, L.D. (2000). Learning from Museums. Visitor Experiences and the Making of Meaning. Lanham, MD. Altamira Press.

Flatt, J.D. et al. (2015) Subjective Experiences of an Art Museum Engagement Activity for Persons with Early Alzheimer's Disease and Their Family Caregivers. American journal of Alzheimer's disease and other dementias 30.4 : 380-389.

Fujwara, D.,Cornwall, T. \& Dolan, P. (2014). Heritage and Well-being. Swindon. English Heritage. https://content.historicengland.org.uk/content/heritagecounts/pub/2190644/heritage-and-wellbeing.pdf

Herbert, D.T. (1989) Leisure Trends and the Heritage Market. In Heritage Sites: Strategies for Marketing and Development, Herbert, D.T, Prentice, R.C. \& Thomas, C.J. eds. Pp 1-15, Hants, Avebury.

Heritage Lottery Fund, 2013. Values and Benefits of Heritage. [pdf] Available at: www. hlf.org.uk/aboutus/howwework/Documents/ValuesandBenefits2012.pdf [Accessed Oct. 2017].

Historic England. (n.d.) Definition: Heritage Value(s). https://historicengland.org.uk/advice/hpg/hpr-definitions/h/536286/ 
Historic England. (2016). Heritage Counts 2016: Heritage and Place Branding. London. Historic England. https://content.historicengland.org.uk/content/heritagecounts/pub/2016/heritage-and-place-branding.pdf

Historic Royal Palaces. (2017). Rethinking heritage: A guide to help make your site more dementia-friendly. London. Historic Royal Palaces. https://www.hrp.org.uk/media/1544/2017$\underline{11-14 \text { rethinkingheritage lowres final.pdf }}$

House of Memories (2017). Home Page. https://houseofmemories.co.uk/

Johnson, J., Culverwell, A., Hulbert, S., Robertson, M. \& Camic, P.M. (2015) Museum Activities in Dementia Care: Using Visual Analog Scales to Measure Subjective Wellbeing,' Dementia , 6(5), pp. $591-610$.

Kinney, J. \& Rentz, C.A. (2005). Observed well-being among individuals with dementia: Memories in the Making@, an art program, versus other structured activity. American Journal of Alzheimer's Disease and other Dementias. 20(4), pp. 220-227.

Lanceley, A., Noble, G., Johnson, M., Balogun, N., Chatterjee, H.J. \& Menon, U. (2012). Investigating the therapeutic potential of a heritage-object focused intervention: A qualitative study. Journal of Health Psychology. 17(6), pp.809-20.

MacPherson, S., Bird, M., Anderson, K., Davis, T., \& Blair. A. (2009). An art gallery access programme for people with dementia: 'You do it for the moment'. Ageing \& Mental Health. 13, pp.744-52.

Maeer, G., Robinson, A. and Hobson, M. (2016) Values and benefits of heritage: A research review. Heritage Lottery.

Mittelman M, Epstein C. (2009) Meet Me at MoMA Program. Research.

Musella, O., Carloni, A., De Marino, L., Di Bartolo, E., Gaeta, G., Di Maggio, P., \& Fasanaro, A. M. (2009). Visual art improves communication and behaviour of AD patients. New trends in Alzheimer and Parkinson related disorders: ADPD, 15-20.

Museums, Libraries and Archives (MLA) Council, 2004. New directions in social policy: health policy for museums, libraries and archives. London: MLA. Available from: http://www.mla.gov.uk/what/publications/ /media/Files/pdf/2004/ndsp health.ashx.

Museums, Libraries and Archives (MLA) Council, 2010. Outcomes framework for museums, libraries and archives. London: MLA. Available at: http://www.mla.gov.uk/what/raising standards/improvement/ /media/Files/pdf/2008/outco mes framework v2.ashx.

National Collaborating Centre for Mental Health (UK). (2007). A NICE-SCIE Guideline on Supporting People With Dementia and Their Carers in Health and Social Care. NICE Clinical Guidelines, No. 42. Leicester. British Psychological Society. 
National Museums Liverpool (2012). House of Memories; National Museums Liverpool Evaluation Report.

Olazarán, J., Reisberg, B., Clare, L., Cruz, I., Peña-casanova, J., Del Ser, T., . . Muñiz, R. (2010). Nonpharmacological therapies in alzheimer's disease: A systematic review of efficacy. Dementia and Geriatric Cognitive Disorders, 30(2), 161-78.

Pawson, R., Greenhalgh, T., Harvey, G. and Walshe, K. (2005) Realist review-A new method of systematic review designed for complex policy interventions. Journal of Health Service Research and Policy. 10, pp.21-34.

Poria, Y., Reichel, A. \& Cohen, R. (2011) World Heritage Site - Is it an Effective Brand Name? A Case Study of a Religious Heritage Site. Journal of Travel Research, 50(5), 482-495.

Prentice, R. (1993) Tourism \& Heritage Attraction. London, Routledge.

Prince, M., Knapp, M., Guerchet, M., McCrone, P., Prina, M., Comas-Herrera, A., Wittenberg, R., Adelaja, B., Hu, B., King, D., Rehill, A., \& Salimkumar, D.(2014) Dementia UK: Second Edition - Overview. London. Alzheimer's Society.

Roberts, S., Camic, P.M., \& Springham. N. (2011). New roles for art galleries: Art-viewing as a community intervention for family carers of people with mental health problems. Arts \& Health: An International Journal for Research, Policy and Practice. 3, pp.146-59

Roe, B., McCormick, S., Lucas, T., Gallagher, W., Winn, A. \& Elkin, S. (2016). Coffee, Cake \& Culture: Evaluation of an Art for Health Programme for Older People in the Community with Dementia. Dementia .15(4), pp.539-59.

Rosenberg, F. (2009). The MoMA Alzheimer's Project: Programming and resources for making art accessible to people with Alzheimer's disease and their caregivers. Arts and Health: An International Journal for Research, Policy and Practice. 1(1), pp.93-97.

Roush, R., Braun, M., Basting, A., Winakur, J., Rosenberg, F., \& McFadden, S. (2010). Using the Arts to Promote Resiliency Among Persons with Dementia and Their Caregivers. In Resnick, B., Gwyther, L., Roberto, K. (Eds.) (2010). Resilience in Aging: Concepts, Research and Outcomes. New York. Springer. pp.105-120.

Salisbury, K., Algar, K \& Windle, G. (2011) 'Do we know enough about the potential of art programmes to improve the quality of life and well-being of people with dementia?' The Journal of Dementia Care.19(3), 33-37.

Silverman, L.H. (2010). The social work of museums. New York. Routledge.

Smiraglia, C. (2015) 'Qualities of the Participant Experience in an Object-Based Museum Outreach Program to Retirement Communities,' Educational Gerontology. 41(3), pp.238-248. 
Solway, R., Thomson, L., Camic, P.M. and Chatterjee, H.J. (2015) Museum Object Handling in Older Adult Mental Health,' International Journal of Mental Health Promotion. 17(4), pp.201214.

Staricoff, R.L. (2004) Arts in health: a review of the medical literature.Arts Council England; Research Report 36. London. Arts Council England.

Thomson, L., Ander, E., Lanceley, A., Menon, U., Noble, G. \& Chatterjee, H.J. (2012a) Enhancing Cancer Patient Well-Being with a Non-Pharmacological, Heritage-Focused Intervention. Journal of Pain and Symptom Management; 44, pp. 731-40.

Thomson, L.J., Ander, E.E., Menon, U., Lancele, A. \& Chatterjee, H.J. (2012b) Quantitative Evidence for Wellbeing Benefits from a Heritage-in-Health Intervention with Hospital Patients. International Journal of Art Therapy, 17(20), pp. 63-79.

UK Department of Health, 2009. New horizons: a shared vision for mental health. Available from: http://www.newhorizons.dh.gov.uk/assets/2010-02-04-

299060 NewHorizons acc2.pdf.

van der Linde RM, Dening T, Matthews FE, Brayne C (2014) Grouping of behavioural and psychological symptoms of dementia. International Journal Geriatric Psychiatry. 29(6), pp.562-568. doi:10.1002/gps.4037

Weiss, P.T., Kayhanian, M., Guilliver, J.S. \& Khazanovich, L. (2017) Permeable Pavement in Northern North American Urban Areas: Research Review and Knowledge Gaps. International Journal of Pavement Engineering, 20(2), 143-162.

Wineinger, N. (2011). Visiting the past: An analysis of the drivers of visiting historic attractions. English Heritage Social and Economic Research working paper. London. English Heritage.

World Bank (2019) Social Inclusion. https://www.worldbank.org/en/topic/social-inclusion Date accessed 17th April.

Wu, S., Lee, A., Tah, J.H.M. \& Aouad, G. (2007) The Use of a Multi-Attribute Tool for Evaluating Accessibility in Buildings: the AHP Approach. Facilities, 25(9/10), 375-389.

Wu, S., Lee, A., Koh, W.W.I., Aouad, G. \& Fu, C. (2004) An IFC-Based Space Analysis for Building Accessibility Layout for All Users. Construction Innovation, 4(3), 129-141.

Zeilig H., Killick J., Fox C. (2014) 'The participative arts for people with a dementia: A critical review,' International Journal of Ageing and Later Life. 9, pp. 7-34. 
